\title{
The research on the present situation and Countermeasures of the cultivation of campus football coaches in Jiangxi Province
}

\author{
Wu Wen, Jun Xiao \\ Pingxiang University, Jiangxi 337055, China
}

\begin{abstract}
Based on the investigation of the current situation, training methods, training system of campus football coaches in Jiangxi Province, and analysis of the main factors that affect the cultivation of campus football coaches, and puts forward three suggestions, such as establishing a diversified training model, improving the competition level of campus football, establishing a scientific training system, in order to provide enough professional teachers and achieve long-term goals for the country to train outstanding football talents.
\end{abstract}

Keywords: Campus football; coaches; training.

\section{Introduction}

In early 2015, the national Ministry of Education issued a new policy, will be selected in the national scope of the campus football characteristics of about 30 schools and about 20000 campus football pilot counties (District). According to a campus football characteristic school needs 10 football coaches, the country will need 200000 football coaches, the current campus football coaches in China, regardless of the quantity or quality are still a big gap. The state general administration of sports bureau chief wei-min yuan said that "a good coaches can cultivate a group of high level athletes; a group of high level coaches can guarantee the sustainable development of sports". Therefore, the cultivation of the campus football coaches is directly related to football reserve talent cultivation in China, directly affected the trend of the development of football in our country.In order to revitalize the long-term development of Jiangxi province football career, to train outstanding, qualified school football coaches talent, in order to carry out a wide range of grassroots football to provide enough professional teachers support, is the key issue to solve the relevant departments in Jiangxi province sports management.

\section{The research object and methods}

\subsection{The research object}

Taking the cultivation of the campus football coaches in Jiangxi Province as the research object, the main research is to participate in the training of the D class football coaches in Jiangxi Province in 2015. Class D football coaches training object is a long time in the school football coaches, the purpose is to improve their practical ability, to further promote the development of campus football.

\section{2 the research methods}

Documentation

A large number of relevant papers on football coaches training and sports management are reviewed by the journal network and network database, which provides a theoretical basis for this study.

Questionnaire survey

Through the questionnaire survey, 15 teachers participated in the training of $\mathrm{D}$ class football coaches to investigate, the main investigation into their previous training, the training of the campus football coaches and some of their own basic situation.

Expert interview method

According to the needs of the research, the 5 experts in Pingxiang football school were interviewed, and the contents of the questionnaire were consulted.

Statistical method 
The statistical analysis of the results of all the survey was carried out, and the data were analyzed by Excel statistical software.

\section{The results and analysis}

\subsection{The current situation of the campus football coaches}

The coaches' age structure

According to the survey, the current Jiangxi province school football coaches to 40 years of young people, about $73.9 \%$ of the survey, the proportion of people over 40 years of age accounted for only $26.1 \%$, which shows that the school football coaches have a very strong plasticity and great development space. The youth of the teachers is a common phenomenon in the school football teaching, which may have a certain relationship with the nature of the football.

The coaches' educational structure

In the investigation of the coaches not from provincial direct retired, they are graduated from college sports or normal physical education professional. From the survey results can be seen, the current school football coaches in the degree of education is still relatively high, the undergraduate education accounted for $60.9 \%$, they have certain advantages in the quality of personal culture. May be related to the current level of school physical education teachers in the preparation of saturation and school recruitment requirements are related, no higher education is not to be hired.

Title Structure

The title structure reflects the ability of a coach to use the theory knowledge in the practice teaching process, and can obtain certain effect in the instruction practice. From the survey, the overall low title of the campus football coaches, assistant level of $47.8 \%$, with the title of only $34.8 \%$, which is related to the nature of education institutions, the title in addition to the work performance, but also a certain number of years of work, which also led to a lot of senior title of the teacher's age is too large, but also very few professors competitive sport.

The sports experience

Most coaches in the study process has been the football generated strong interest, both to maintain long time of 2 - 3 years related training, participated in the football match, which represent the school contest $65.2 \%$; after graduation or work in teaching practice of football more than 5 years accounted for $82.6 \%$; but their have few experience to lead game after work. The main reason may be lack of the organization in the football match between schools.

\subsection{The current situation of the cultivation of the school football coaches}

The training mode

Due to the limitation at all levels of the school's own development, a lot of football coach also wears the role of physical education teachers, there can be no full-time football coach, which also determines the campus football coach from the product of higher education are from sports colleges and universities or is normal sports education professional graduate, also headed the experience less engaged in school football coaches work and personal expertise or interest.

The acceptance of re education

Due to the current campus football coaches from college graduates, the theory of knowledge, but less practical experience, after the work of their education is the main way to enhance their personal level, in the study period or during the work has also received a football coach related education or training, only $26.1 \%$ of people have received similar training. This also reflects that the training mode of the school football coaches is too single, which is not conducive to the improvement of the level of coaches.

\subsection{The current situation of the training of the school football coaches}

The registration form

After talk with all coaches, many training coaches are each primary school independent registration or recommended. The school agreed to the newspaper comes up, not personally enroll. On the one hand, no financial support is difficult to achieve, both of which lead to the only units 
selected. At the same time, they also feel that such a training opportunity is too small, before there is little opportunity to contact, the exchange between the coaches is very little.

The training course arrangement

The training course content includes the quality of coaches, safety and health, training principle, the coach's guidance requirements and the requirements of the competition, the practice of the principle, basic techniques, offensive and defensive, rules, and 4vs4, $5 \mathrm{vs5}$ small venues.

The assessment method

The content of the examination includes theory and practice exam, the full score of 100 points, the theory and practice of the test must be passed the final training, in order to get the appropriate coaches certificate.

The training satisfaction

After a week of training, all coaches have achieved qualification certificate, but on the satisfaction survey on the training, for training content and arrangement of the investigation, only $65.2 \%$ satisfaction, in addition, $30.5 \%$ is not satisfied, may be some coaches that combination of theory and practice courses is not enough, some purely theoretical content is more.

\section{The factors affecting the training of the football coaches in the school}

\subsection{The education system factor}

Chinese education system led directly to the without education is not to teach, any school, especially suitable for campus football to carry out primary and secondary schools, in order to ensure the quality of teaching, the introduction of talent must first consider is education and professional counterparts, although the overall school football coaches qualifications increase, but the lack of practice notch ability training will inevitably lead to the work after a period of time is to grope for a period.

\subsection{The school self-development factor}

Now the school leaders, students and parents to pursue high marks and entrance rate, sports can only become a waste of time, there is no parents are willing to send students to take part in the school football training, which has led to the very difficult to carry out the campus football lost the survival of the soil. School will not in football put too much time, energy and financial resources, football coaches is no chance to notch training.

\subsection{The training mechanism}

Training of soccer coaches originally belonging to the Chinese Football Association, but in view of the campus football coaches, due to the particularity of training object, finally only can responsible for the General Administration of sport of China. At the same time, it is difficult to ensure that the post training of the school football coaches and the improvement of the teaching quality.

\subsection{The dynamic factors}

Most of the school football coaches are both coaches and sports teacher, not only engaged in heavy physical education, but also responsible for the daily training in football, and there is no significant effect to engage in campus football, these factors make coaches work without much pressure.

\section{The countermeasures and suggestions}

\subsection{To build a diversified training model}

Campus football is gradually carried out in recent years, but also the Chinese football reserve forces from national institutions to change to the primary school training, and effectively improve the quality of the future football players. As a result, the requirements of the campus football coaches are also getting higher and higher. We must change the single training model of the Provincial Sports Bureau, set up the direction of football coaches professional, hire retired football players, and better service for local football. 


\subsection{Improve the level of school football match}

With the increasing influence of the campus football, the relevant groups of school football match must be able to keep up with the trend. The young people can organize the 5 person system, the 6 system of events, can also take the method of shortening the time or reducing the competition venue, improve the students' participation in the football match. Only in this way, the charm of the campus football can be reflect, the social value of the work of coaches and personal achievements can be recognized. Through the competition, it can also make the coaches' coaching ability to get a certain test, which can make them think and reflect in practice, and further have a purpose, a sense of improving the professional ability of the individual.

\subsection{To establish a scientific training system}

A system includes many aspects, it's hard to solve all the problems only by the Provincial Sports Bureau to set up the campus football coaches training institutions or organizations. Set up the system of provinces and cities two levels of joint management, and take unified management on training institutions, training courses, form, time, cost, teaching material, reform the existing examination system, At the same time, improve the registration system of coaches, coaches have obtained the certificate to continue education, through lectures, seminars, reports, communication and the use of remote network.

\section{References}

[1] QiHui Zhe. Under the background of campus football school football teaching present situation and countermeasure research, campus football layout at the provincial level city of Henan province as an example [D]. Zhengzhou: Henan university, 2014

[2] Yaohui Li. Talents in college football coaches and training status and influence factors of research [D]. Beijing: Beijing sport university, 2008

[3] Yixuan Li. The campus football coaches in jilin area develop investigation and analysis of the status quo of study [J]. Journal of sport science and technology literature bulletin, 2014, 22 (1): 104-105

[4] XiaoYu Liu. Soccer coaches training in our country present situation and countermeasure research [J]. Journal of Wuhan sports college, 2009 lancet (10): 70-74 